\title{
Impacts of service robots on service quality
}

\author{
Ai-Hsuan Chiang ${ }^{1} \cdot$ Silvana Trimi ${ }^{2}$ (1)
}

Received: 18 July 2020 / Accepted: 31 July 2020 / Published online: 7 August 2020

(c) Springer-Verlag GmbH Germany, part of Springer Nature 2020

\begin{abstract}
With rapid advances in technologies, especially in artificial intelligence, smart sensors, big data analytics, and robotics, the service industry began introducing robots to perform a variety of functions. While the main purpose of deploying robots has been productivity improvement, the current COVID-19 pandemic has brought more urgent purpose, providing contactless service for social distancing. This study explores the service quality provided by robots based on real data in a hotel setting. A sample of 201 guests provided their expected service quality by robots and the actual performance experience after the service. We analyzed this relationship using importance performance analysis (IPA) and the Technique for Order Preference by Similarity to an Ideal Solution (TOPSIS). The results revealed that customers' top priorities for robots' service quality are assurance and reliability, while tangible and empathy were not as important. Customers were not satisfied with robots' responsiveness, but this construct was found to be a low priority.
\end{abstract}

Keywords Service quality $\cdot$ Service robot - Artificial intelligence $\cdot$ TOPSIS · Importance-performance analysis

\section{Introduction}

Traditionally, service providers have been humans. In the advent of advanced digital technologies, especially artificial intelligence (AI) and Internet of Things (IoT), and the current pandemic situation, smart robots are increasingly replacing employees to provide contactless services (Hrynowski 2020; Huang and Rust 2018; Wirtz et al.

Silvana Trimi

silvana@unl.edu

Ai-Hsuan Chiang

eliot@mail.mcu.edu.tw

1 Department of International Business, Ming Chuan University, 250 Zhong Shan N. Rd., Sec. 5, Taipei, Taiwan

2 Department of Supply Chain Management and Analytics, College of Business, University of Nebraska - Lincoln, Lincoln, NE 68588-0405, USA 
2018). For example, smart robots have been deployed in some hotels (Palvia and Vemuri 2016), retail stores (Grewal et al. 2018), airports, meal delivery, etc.(Frick 2015; Lee et al. 2009) The current COVID-19 pandemic crisis is proving the usefulness and expanding roles of robots in a wide range of services and industries. Service robots can alleviate the workload of first responders in hospitals while keeping them safe from virus infection, perform tasks so that humans can practice social distancing, execute delicate procedures that not many medical staff have the skills or stamina to perform (Matthews 2020).

Robots can be classified into industrial robots and service robots. Industrial robots are used primarily for manufacturing applications in factories and warehouses. Service robots are mechanical devices that can mimic human behaviors to provide, autonomously or semi-autonomously, services to humans (Haidegger et al. 2013; International Federation of Robotics 2016; Lechevalier et al. 2014). Robotics Tomorrow defines service robots as "semi-autonomous or fully autonomous robots that have some mobility and interact with people, usually in a retail, hospitality, healthcare, warehouse or fulfillment setting". Based on this definition, industrial robots can also be considered service robots if they perform nonmanufacturing work. For example, robotic arms can be used in bars to dispense drinks or to assist doctors in performing surgery in a hospital (Haidegger et al. 2013).

The abilities of service robots have gradually exceeded the performance of human service providers in certain areas, e.g., memory, computing power, physical strength, and handling unpleasant or dangerous tasks. However, those service robots have a limited level of AI to provide a wide variety of services. AI can be classified into four categories: mechanical, analytical, intuitive, and empathetic (Huang and Rust 2018; Laowattana 2020). Today's service robots, while their applications have seen a significant increase during the current pandemic, are efficient and therefore used mostly for the first two level of intelligence, as they still lack proficiency in the two high order intelligence.

The intuitiveness and empathy intelligence of AI have yet to be fully imbedded in service robots to match or surpass that of humans (Huang and Rust 2018). Currently, it is difficult for robots to independently perform complicated services in situations that require intuition, judgment, and empathy (Huang and Rust 2018). For example, service robots in hotels may have difficulty responding to customer complaints. If the service requires experience and authorization, it may be difficult for robots to use wisdom based on experience, emotion, and human touch. Therefore, today, there still exists a gap between the level of service provided by robots and that by humans, sometimes large enough to make them useless. For example, it was reported that some Japanese hotels replaced service robots with humans because of the poor service quality (Gale and Mochizuki 2019). Therefore, in the current state of technologies, robots are not only unable to completely replace human servers even when their efficiencies are better than humans, but they also cannot function without humans. Thus, robots and human can and should augment each other to provide quality service to customers (Baldwin 2019).

Besides the technical issues involved, robots that have face-to-face encounters with customers must be visually acceptable to customers, an additional requirement of being trusted by humans (Talk and Lew, 2020). The degree of anthropomorphism 
(physical similarity to humans) affects the level of trust and acceptance, and this requirement depends on the type of service and comfortness (familiarity) with robots (Talk and Lew 2020). Thus, the more a robot looks like human, the more people would consider it 'creepy'. Perceived warmth is important to the consumer, as well as getting used to their presence. For example, in the current pandemic crisis, people accept robots as lifesavers, regardless of their appearance.

Most studies on service robots to date have focused on their design and development (Lechevalier et al. 2014). There is a paucity of empirical studies on the quality of service provided by robots, how to use service robots to meet customer needs and expectations in services. It is imperative for businesses to understand the strengths and shortcomings of current service robots in order to determine the most effective way to not only design but also deploy them in customer service processes. Thus, the purpose of this study is to investigate the service quality of robots in meeting customers' expectations and needs. Specifically, this study seeks answers to the following the questions: (1) Is there a discrepancy between what is important to the customers (their expectations) and the actual performance of service robots (customer satisfaction with service robots)? (2) After identifying the gap between what is important/expected and the actual performance experience, what specific quality aspects of service of robots need to be strengthened? To explore these questions, we used a real-world case of Chase Walker Hotel in Taiwan which is a good example to explore the performance of service robots because all of its services are provided completely by robots, with no human service staff. The findings of the study are expected to make contributions to the service robot literature and provide useful new insights to service organizations in their strategies to effectively deploy service robots for positive customer experience.

The rest of this paper is organized as follows. In Sect. 2, we provide the theoretical background of this research, development of service robots, and the service quality provided by robots. Section 3 discusses the research method followed by the research results in Sect. 4. Section 5 concludes the study with a summary of the findings, implications of the results, limitations, and future research needs.

\section{Literature review}

\subsection{Service robots}

Regan (1963) noted that there are four characteristics of services: intangibility, heterogeneity, indivisibility, and perishability. In recent years, researchers have also advocated customer participation as an additional characteristic of service, which has also been noted to be the main source of service variation (Sampson 2001). The above five characteristics can further be elaborated with the presence or absence of customer inputs (Chase 1978; Lovelock 1992; Sampson 2001; Vargo and Lusch 2004). In the extant literature of service business both the provider and the consumer of service are generally assumed to be humans. However, with the current new advances in technologies, especially robotics, services can be provided not only by people but also machines, alone or along with each other. Therefore, the concept 
of service has expanded from just human-2-human interactions to human-2-roboot/ machine interactions (Huang and Rust 2018). It has been common for a while now to find unmanned information kiosks, automatic check-in systems at airports, robot barista in a coffeehouse, and information robots in shopping malls.

The current Covid19 pandemic spread has forced many companies, especially those in travel and food industries, to quickly develop contactless service solutions by using robots. Robots are used to reduce in-person interaction (employee-customer, employee-employee); serve food and drinks; provide no touch-surfaces solutions (e.g., using apps instead of printed menus, using contactless payment systems, such as Apple Pay instead of credit cards, using smart phones for: opening hotel door rooms, controlling room temperature, adjusting lights, operating TV, etc.); provide virtual tours, etc. (O’Neill 2020).

Service robots are different from industrialized robots in appearance and functions. While industrial robots are used for manufacturing and usually are in large scale-machines, service robots are used to automate menial, repetitive, cumbersome, complex, dirty, dangerous, and time-consuming tasks (Calderone 2019; Matarić 2017). At present, especially during the pandemic, robotics technology is developing rapidly. It is predicted that service robot market will reach $\$ 37$ billion by 2021 (Calderone 2019). However, the application of robotics technology is still at the early stage in service organizations (Lechevalier et al. 2014). The development and use of service robots are complex because robotics technology is based on a crossdisciplinary science (Zalama et al. 2014) and it requires new and innovative thinking of the relationships among different entities (Novak and Hoffman 2019). In addition, for a widespread use of service robots, customer inputs and co-creation are necessary to ensure that robots provide what customer want with quality service (Baisch et al. 2017; Čaić et al. 2018)..

According to the knowledge-based view, organizations ought to continuously create and transform knowledge for sustainable competitive advantage (Kogut and Zander 1992). In the age of service-dominant logic, knowledge and innovation of services provided to customers have become a key source of competitive advantage (Gidhagen et al. 2011). Through advances in robotics and AI organizations are continuously endeavoring to provide new service value to customers. While in the traditional customer service situation, service is a process that involves a series of activities and interactions between humans (employees and customers) (Ray et al. 2005; Setia et al. 2013), in the service robot environment, service is a process that involves hybrid interactions between humans and robots.

Consumers value different dimensions of service quality. For example, some customers desire speed and accuracy of services while others care more about friendly and personal attention. With service robots, consumers' expectations for both the kind of services and their quality change (Edvardsson et al. 2018; Lee and Lee 2019). Therefore, service quality provided by robots and their importance to the customer are affected by both technical capability of robots as well as customer expectations (Fig. 1). Before robots are deployed for services, organizations must understand what customers want and expect regarding service quality provided by robots. Thus, in this paper we explore the important quality features of service robots that customers expect and need. 


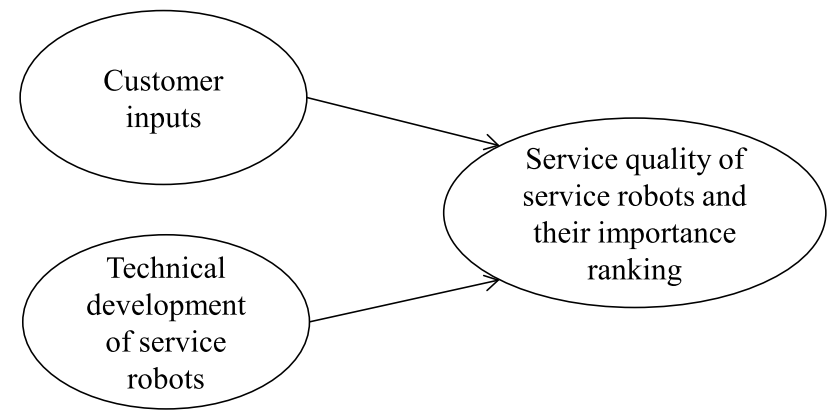

Fig. 1 Research conceptual framework

With the increasing dominance of the service industry in recent years, the development of service robots has flourished (Garcia et al 2007). Accordingly, service robots have been defined in different ways. Wirtz et al. (2018) defined service robots (SR) as "system-based autonomous and adaptable interfaces that interact, communicate and deliver service to an organization's customers." The International Organization for Standardization (2012) defined a service robot as "that performs useful tasks for humans or equipment excluding industrial automation applications" (ISO 8373). Robots range from those that are partially autonomous requiring human-robot integration, to fully autonomous ones that perform tasks without human intervention. They may have some mobility and interact with people, execute service tasks by mimicking human workers, usually in retail stores, hospitality businesses, healthcare providers, warehouses or fulfillment centers (e.g., Choi et al. 2019; Koceski and Koceska 2016; Lee and Lee 2019). Some AI-enabled advanced robots perform in more demanding settings such as space, war zones, policing, agriculture, etc. (Bolton et al. 2018).

Service robots represent the convergence/application of many technologies, including electronics, computers, machinery, communications, localization, navigation, applied psychology, sociology, and biology (Zalama et al. 2014). New advances in robotics technology include such sophisticated areas as intelligence, voice recognition, mobility and control, and image recognition (Lechevalier et al. 2014). Thus, the domain of robots has expanded to a wide range of sectors for a variety of jobs and services (Lechevalier et al. 2014). Service robots can be classified into two types: (1) Professional robots that can handle certain complex tasks such as operating automatic processes, performing dangerous tasks, enhancing efficiency (lowering cost and downtime), and improving productivity (Calderone 2019; Lee et al. 2009); (2) Personal service robots that mainly provide services to humans (Darling 2012; Reiser et al. 2009). Robots are so prevalent now that people even regard them as companions or friends (Leite et al. 2013). With the advances in robotics technology, the relationship between technology and people may need reimagining. 


\subsection{Service quality of robots}

In the past, service research has focused on the customer's view of a service provided by front-line employee in a physical place. However, with the rise of e-commerce, the focus of recent research has shifted to customer views on the service quality of electronic platforms (Choi and Kim 2018; Hung et al. 2019; Santos 2003). The service quality of robots, while it involves application of new technologies, is still in the realm of brick and mortar facilities. Therefore, the performance of service robots, as a "front-line employee in a physical place" may affect user satisfaction; thus, it needs to be measured (Bartneck et al. 2009). Observing the customer's behavior is an objective and credible way to measure the user's perception of the service quality of robots (Kooijmans et al. 2007).

Service quality indicates the level of customers' perception that the service met their goals (Asubonteng et al. 1996; Hemmington et al. 2018; Lewis and Mitchell 1990; Wisniewski 1996). Service quality is determined by the consumer's overall assessment of the service (Parasuraman et al. 1991). Service quality is a subjective cognitive value determined by the customer rather than an objective measure (Garvin 1984; Grönroos 1984). Grönroos (1990) argued that customers expect a certain quality of service before they receive it - the expected quality; after the service is performed, customers develop feelings about the service experience, the experience quality. Previous studies examined different constructs of service quality and compared the gap between the actual services provided by the company with that of customers' expectations (e.g., Churchill and Surprenant 1982). At present, most research related to service quality is mainly focused on measuring customers' opinions on the performance of the service delivered (Athanassopoulos et al. 2001; Bloemer et al. 1999; Orel and Kara 2014; Svensson 2006; Vanniarajan and Anbazhagan 2007).

Service quality is seen as an organizational asset and is considered a key component of organizational performance (Al-Hawari and Ward 2006). Parasuraman et al. (1985) proposed a measure of service quality. Parasuraman et al. (1988) modified the original ten service quality constructs into five constructs for SERVQUAL, a widely accepted and applied model to measure service quality that includes: reliability, responsiveness, assurance, empathy and tangibles (Berry et al. 1990; Parasuraman et al. 1988, 1991; Shahin 2006; Zeithaml et al. 1988, 1993). Expectation disconfirmation theory (Oliver 1980; Oliver and DeSarbo 1988) suggests that when a customer's expectation for the service is higher than the actual service experience, the customer would be dissatisfied; in contrast, when the customer's expectation for the service is lower than the actual experience received, the customer would be satisfied. Teas (1993) argues that satisfaction refers to a customer's perception after receiving a service.

\section{Methodology}

\subsection{Data and sample characteristics}

The real-world case examined in this study is Chase Walker Hotel, the first fully robotic service hotel in Taiwan. There are no human service staff in the entire 
building. Tourists can contact the hotel's human office staff for only few cases; otherwise, guests do not see any employee during their stay. Chase Walker Hotel has a robotic service that includes an automatic check-in system in the lobby (Fig. 2) and a robotic arm that stores luggage next to the lobby (Fig. 3). Guests can check room availability or use reservations to check-in at the automatic check-in counter when entering the hotel. After the guests input their personal information in the system, they are issued auto-sensing room cards that activate their access to their rooms and other facilities. The automatic check-in system can perform the work of the regular counter service. Although it does not have a human receptionist, it has some imbedded human intelligence. A guest can use the auto-sensing room card to activate the robotic arm to deposit his/her luggage. The robot will store the luggage in a secure slot when the customer places it at a designated location. The guest can retrieve the luggage after returning to the hotel using the same procedure. The luggage storage robot arm performs the work of bell service workers. Thus, these two systems can be labeled as service robots.

The data for this study was collected through questionnaires given to guests of Chase Walker Hotel who used the robotic service. Guests were given two questionnaires with the same questions but at two different times for different reasons (therefore, questions were formulated as such): the first questionnaire was given to guests before they entered the hotel (thus, before they used robot services) and questions were about customers' expectations of the hotel's robotic services. The second questionnaire was given to guests after their stay in the hotel (thus, after they used robot services) but this time questions (same questions as the first time) were about their evaluation of the actual performance (satisfaction with their service experience) of service robots. Then the first and second part of the questionnaire for each guest were matched to examine the differences between expectations (importance

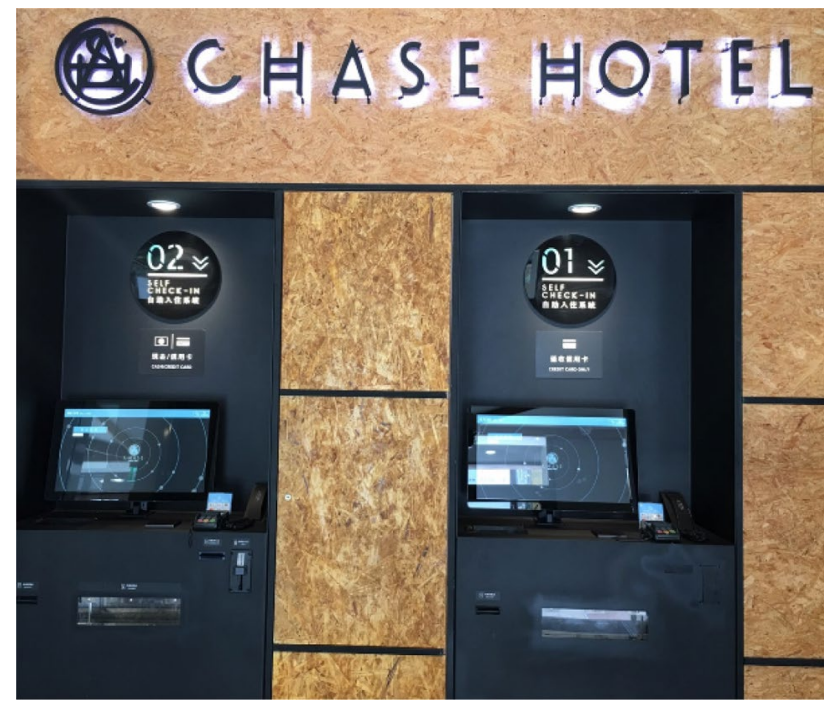

Fig. 2 An automation check-in system in the Chase Walker Hotel 


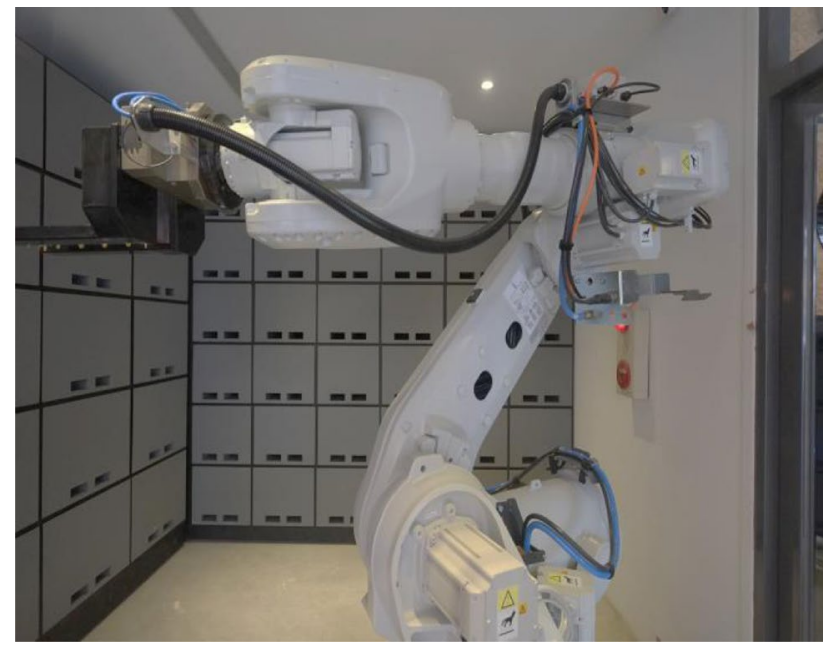

Fig. 3 A robotic arm to deposit luggage in the Chase Walker Hotel

of different service features) and actual performance (satisfaction after the experience) of service robots. To increase data collection, we provided an incentive to participants (encouraged them to list their e-mail addresses in each questionnaire to participate in a drawing to win several electronic products). This device (having participants provided their emails in both questionnaires) allowed us to match the two questionnaires for each responding guest and examine the gap (expectation vs. actual) on the service quality of robots.

Most of the questionnaire items were derived from previous studies. A double translation protocol was undertaken in developing the questionnaire (Harkness 2011). A bilingual marketing professor translated the questions in the original English version of the questionnaire into Chinese; then, an operations management faculty, who is also bilingual, translated the Chinese version back into English. We compared the two English versions of the questionnaire and found no significant differences between them. Before finalizing the questionnaire, we pretested it with 30 individuals who have stayed at hotels with service robots as a pilot test. We found two questions that confused respondents, so they were revised in the final questionnaire. The data collection was conducted during a 3-month period, June to September 2019. A total of 280 sets of questionnaires were distributed. The questionnaires that could not be matched as a set were excluded. The final sample size was 201 valid questionnaire sets, a response rate of $71.2 \%$. Table 1 presents the sample profile. The majority of respondents was female $(61.7 \%), 20-29$ years of age $(66.7 \%)$, working in the service sector (34.3\%), and with university-level education $(81.1 \%)$.

\subsection{Measurement}

The items of the constructs in this study were adopted from previous studies (Cronin and Taylor 1992; Parasuraman et al. 1985, 1988, 1991). The questionnaire included 
Table 1 Demographics of the respondents

\begin{tabular}{lcl}
\hline Demographics of sample & $\begin{array}{l}\text { Number of obser- } \\
\text { vations }\end{array}$ & Percentage (\%) \\
\hline Gender & 77 & 38.3 \\
Male & 124 & 61.7 \\
Female & & \\
Age & 16 & 8.0 \\
Less than 20 & 134 & 66.7 \\
20 to 29 & 43 & 21.4 \\
30 to 39 & 8 & 4 \\
More than 40 & & \\
Occupation & 65 & 32.3 \\
Student & 15 & 7.5 \\
Civil service & 69 & 34.3 \\
Service sector & 20 & 10 \\
High-tech industry & 32 & 15.9 \\
Others & & \\
Education & 20 & 10.0 \\
High school or below & 163 & 81.1 \\
Bachelor's degree & 18 & 9.0 \\
Master's degree or up & & \\
\hline
\end{tabular}

five constructs that measure the expectations and actual performance experience of robot service. These five constructs are: tangibles, reliability, responsiveness, assurance, and empathy (Table 2). Tangibles include physical facilities, equipment, and appearance.

Reliability indicates whether the service robots appear to reliably perform the committed services. Responsiveness indicates whether service robots help customers and deliver immediate service. Assurance is the ability of service robots to perform tasks with expertise, politeness, and trust. Empathy is providing care and personal attention to customers during the service. The measurement scale used in the questionnaire was based on a 7-point Likert scale $(1=$ strongly disagree, $7=$ strongly agree). After two experts examined the appropriateness of the semantics of measurement items, we decided to delete several items that were not suitable for this study involving service robots. For example, we deleted the question about neat appearance of hotel employees as there is no relevant anthropomorphic feature with service robots. The questionnaire items are available from the first author upon request.

\subsection{Common variance bias}

To avoid the single response bias and decrease the possibility of common method variance (CMV), the two questionnaire parts, the consumer expectations of robot services and the performance experience after receiving the services, were 


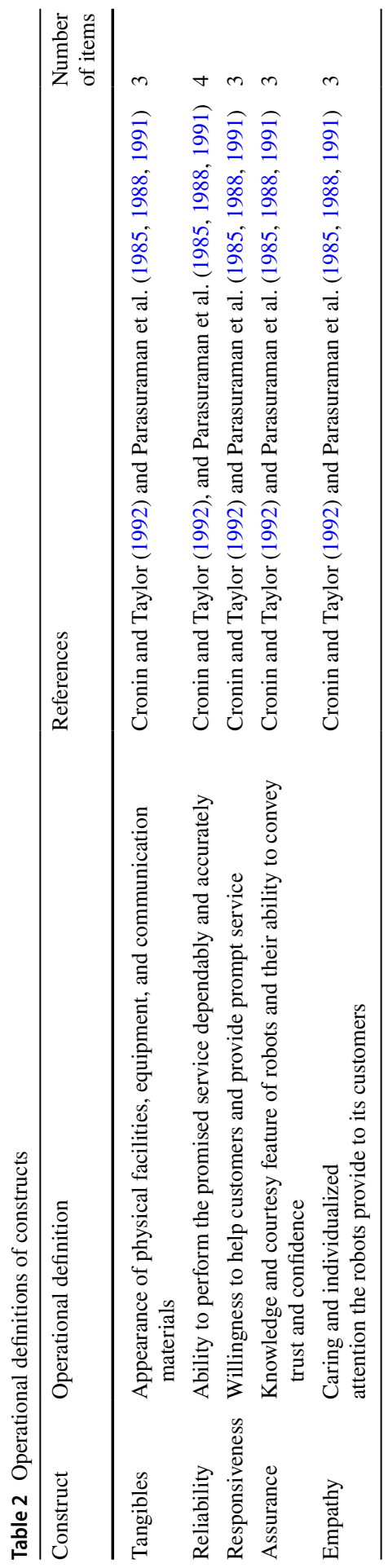


completed by respondents at different points in time. Additionally, the respondents filled out the questionnaire at the site of robotic services.

This study also handled the potential for CMV in the following manner. First, an analysis of Harman's single-factor test for common method bias was applied. Podsakoff and Organ (1986) showed that if CMV is a serious problem, a factor analysis will have either a single factor or one factor will affect most of the covariance of the predictor. Through principal factor analysis, the measurement items in this study yielded ten factors with eigenvalues greater than 1.0, accounting for $72.3 \%$ of the total variance. The first factor accounted for $28.5 \%$ of the variance. Thus, common method variance is not a serious problem for the study data.

In addition, to evaluate common method bias, confirmatory factor analysis (CFA) was applied to Harman's single factor model (Sanchez and Brock 1996). The fit indexes for the CFA model, including $\chi 2 /$ d.f. $=4.721$, AGFI $=0.326$, NNFI $=0.386$, $\mathrm{CFI}=0.387$, RMSEA $=0.136$, and $\mathrm{SRMR}=0.169$, were unacceptable. The results were worse than those of the measurement model, indicating that a single factor was unacceptable.

\subsection{Analysis approach}

To determine the importance of service quality of robots, we used Technique of Order Preference Similarity to the Ideal Solution (TOPSIS), a widely applied multicriteria decision analysis method (Hwang and Yoon 1981). The programming language $\mathrm{R}$ was applied to execute a TOPSIS program. TOPSIS calculates the weights of each construct of service quality. These weights were sorted to determine customers' priorities on service quality dimensions in terms of expectations and actual experience of service provided by robots. To perform the reliability and validity tests we used SPSS 22.0. To examine whether the difference between expectations and actual performance was significant, we used the dependent $t$-test for paired samples of each subconstruct of service quality of robots. Finally, we used importance-performance analysis (IPA) to examine the relationship between the importance (expectation) and satisfaction of robots' service quality (actual performance experience).

\section{Results}

\subsection{Reliability and validity}

This study examined the descriptive statistics, reliabilities, and inter-correlations among the study variables (Table 3). Concerning Cronbach's alpha, 0.6 is the suggested minimum acceptable value (Norman and Streiner 2008). The results show that Cronbach's alpha values were between 0.643 and 0.889 , indicating that the measures are all reliable (Table 3 ). The fit indexes of the confirmatory factor analysis (CFA) were as follows: $\chi^{2} / \mathrm{d} . \mathrm{f}=1.913, \mathrm{IFI}=0.904, \mathrm{CFI}=0.902, \mathrm{NNFI}=0.884$, $\mathrm{SRMR}=0.062$, and RMSEA $=0.068$. These indexes show that the data fit well with our research model. In addition, the square root values of the average variance 
extracted (AVE) were greater than the correlation coefficients between constructs (Table 3), thus indicating adequate discriminant validity.

\subsection{Paired samples t-tests}

This study used SPSS software to perform paired-samples $t$-tests to determine whether there exists a difference between the customers' expectations and the actual experience of service robots. As shown in Table 4, there were significant differences between expectations and performance experience for reliability, responsiveness, and assurance, but no significant differences for tangibles and empathy. The paired samples $t$-test for tangibles were nonsignificant $(p>0.05, t=-1.511)$. The results for reliability were negative and significant $(p<0.001, t=-4.622)$, indicating that customers' experience of that performance reliability of service robots (i.e., their ability to accurately perform the service) was less than expectations. The results for responsiveness were negative and significant $(p<0.01, t=-3.104)$, which implies that customers perceived that service robots' response speed was not par to their expectations. The results of the test for assurance were negative and significant $(p<0.01, t=-3.315)$. Therefore, customers believed that their expectations in confidence and trust in professional knowledge, affinity, and ability of service robots were not higher than actual experience. The results for empathy were also negative but nonsignificant $(p>0.05, t=-0.814)$.

\subsection{TOPSIS ranking analysis}

The results shown in Table 5 indicate that customers pay a different level of attention to each construct. When customers evaluate their expectations and the actual performance of the robot, they pay the most attention to tangibles, followed by reliability, assurance and so on. In addition, responsiveness and empathy showed the lowest rankings in both customer expectations and actual performance of service robots.

\subsection{Importance-performance analysis (IPA)}

The results of IPA are shown in Fig. 4. The horizontal axis is the ranking score of importance obtained by TOPSIS, where the ranking scores of greater than 0.5 are considered important. The vertical axis represents the performance, which in this study is the perceived customer satisfaction of the robot service performance, obtained by the paired samples $t$-test results. If the paired samples $t$-test is positive and significant, customers are considered to be satisfied with the subconstruct; based on our results none of our dimensions fit in this category. On the other hand, if the paired $t$-test is negative and significant, customers are dissatisfied with the subconstruct; three of our dimensions (responsiveness, assurance, and reliability) fall in this category and are shown below the dashed line in Fig. 4. The results also showed that assurance and reliability are in the quadrant of high importance and low satisfaction, which indicates that much improvement is needed for these two constructs. 


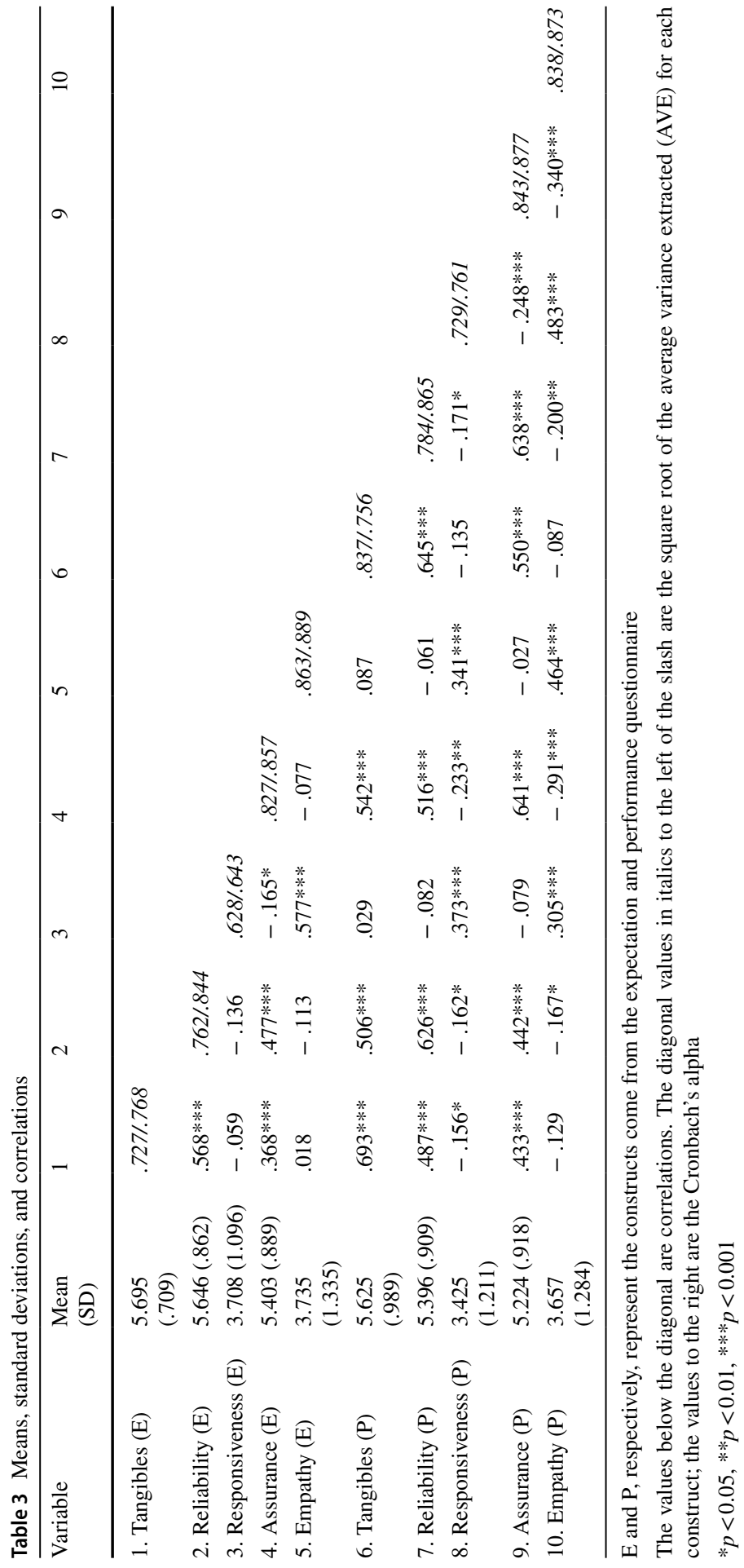


Table 4 Paired samples t-test

\begin{tabular}{llll}
\hline Construct & $\begin{array}{l}\text { Performance } \\
\text { Mean (Std. deviation) }\end{array}$ & $\begin{array}{l}\text { Expectation } \\
\text { Mean (Std. deviation) }\end{array}$ & \multirow{2}{*}{-value } \\
\hline Tangibles & $5.625(0.989)$ & $5.695(0.709)$ & -1.511 \\
Reliability & $5.396(0.909)$ & $5.646(0.862)$ & $-4.622^{* * *}$ \\
Responsiveness & $3.425(1.211)$ & $3.708(1.096)$ & $-3.104 * *$ \\
Assurance & $5.224(0.918)$ & $5.403(0.889)$ & $-3.315^{* *}$ \\
Empathy & $3.657(1.284)$ & $3.735(1.335)$ & -0.814 \\
\hline
\end{tabular}

$* p<0.05, * * p<0.01, * * * p<0.001$

$\mathrm{n}=201$

Table 5 Results of TOPSIS ranking

\begin{tabular}{llllll}
\hline \multirow{2}{*}{$\begin{array}{l}\text { TOPSIS } \\
\text { ranking }\end{array}$} & Performance & & \multicolumn{2}{l}{ Expectation } & \\
\cline { 2 - 2 } \cline { 5 - 6 } & Sub-construct & Ranking score & & Sub-construct & Ranking score \\
\hline 1 & Tangibles & 0.772 & & Tangibles & 0.800 \\
2 & Reliability & 0.695 & & Reliability & 0.747 \\
3 & Assurance & 0.640 & & Assurance & 0.673 \\
4 & Responsiveness & 0.388 & & Responsiveness & 0.297 \\
5 & Empathy & 0.295 & & Empathy & 0.276 \\
\hline
\end{tabular}

Responsiveness is placed in the quadrant of low importance and low satisfaction, indicating that this construct has a lower priority for improvement. As for empathy and tangibles, they fall between the two dashed lines, which indicates that customers' expectations were not significantly different from the degree of satisfaction about the performance of service robots for these dimensions. This means that the degree of importance that customers feel about empathy (low) and tangibles (high) seemed to have no significant impact on customer satisfaction with service robots' actual performance.

\section{Discussions}

The study of customer behavior and satisfaction regarding service robots is the core information necessary for designing service robots to improve their performance and acceptance by human (Sheppard et al. 2017, 2018). Our study collected and analyzed empirical data to ascertain the gap between what customers expect and what they actually experience from service robots (how satisfied they are with the service quality) and identify the degree of importance of each quality construct. The results of our study are expected to provide valuable insights to the designers and producers of service robots, as well as strategic information to organizations that are planning to implement service robots to provide new value to their customers. 


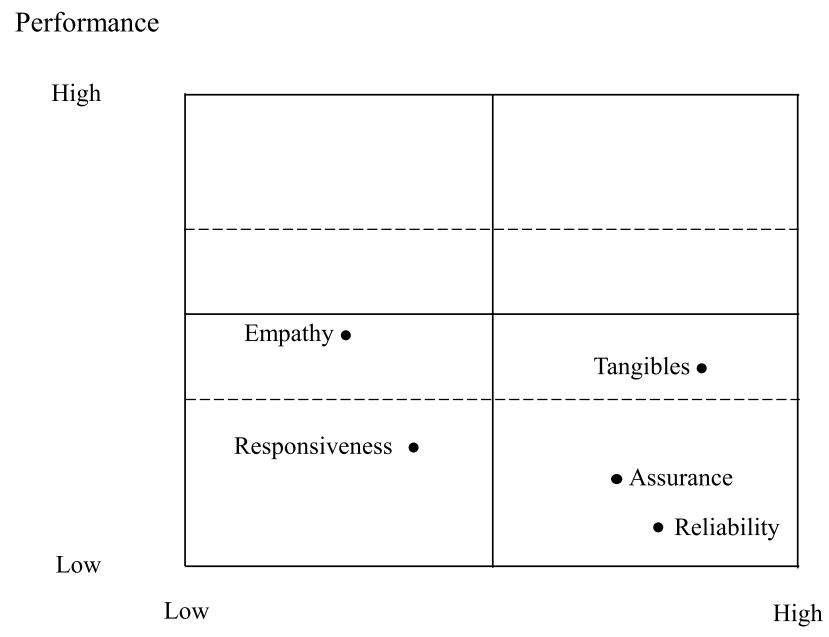

Importance

Fig. 4 Importance-performance analysis for the service robot

Our study found that the level of service provided by robots does not meet customers' expectations when it comes to quality constructs of reliability, assurance, and responsiveness. The implication of this result is that customers' trust and confidence in service robots suffer, when they are not satisfied with robots' reliability and assurance. When customers are not satisfied with responsiveness of robots, it means that they are not happy with the speed of service provided by robots. The service quality of responsive robots means that customers expect robots provide instantaneous service. The response ability is intuitive intelligence related to a given situation which is a relatively advanced ability for AI technology that currently is not widely available as yet (Huang and Rust 2018). This study proved this by showing that customers are not satisfied with the level of responsiveness of service robots. However, at presence, as our study results showed, customers do not consider it to be important, proving that responsiveness is not as critical in services as compared to that for industrial robots.

In our study, the tangibles and empathy constructs of service quality provided by robots did not show significant differences in their ratings of customer expectations and the actual performance. Tangibles are important to customers as physical appearance and interface features of robots and may affect users' perception of robots' anthropomorphism and the quality of the human-robot interactions. Not every task or service would have the same demand and need when it comes to the level of tangibles. An area of contention in the service process is the matching a task/job/service with right visual design (Waytz et al. 2010). For example, a routine or less complex work may require less tangibility (e.g., information kiosks, or check-in stations). However, consumer-facing robots need to have visual design that fosters customer trust and acceptance by humans. Perceived warmth, for example, is important for human acceptance of robots. However, here too, it depends on the 
kind of tasks to be performed by robots: for example, less is required in restaurants and grocery stores, but more is imperative in healthcare or elderly care. The current COVID19 pandemic has greatly increased the level of robot usage. As robots are necessary or people would rather have encounters with robots than humans, regardless of their appearance robots are now trusted and accepted as lifesavers (Talk and Lew 2020). Future research will delve more on these issues: determining what consumers think about tangibles, what they consider as friendly, trustworthy appearance, and for what type of tasks.

Robots with empathic intelligence can provide care and personal attention to humans. The emotional capabilities of robots may have different effects on the service quality for different service types. Yet, in our study, customers perceived empathy as the least important quality they expect from service robots. This is perhaps because of the setting of our study (hotel) or that we are still at early stages when it comes to the development potential of human-robot interactions with respect to empathy. One possible reason for this delay is that robots need to sense and understand the emotional state of the user, which still is a very challenging task. Robots only have artificially programmed emotions without emotional intelligence, and our study results are consistent with the arguments of Keating et al. (2018). There have been some notable improvements in emotion recognition (e.g., Softbank's Pepper) using different modalities such as vision, speech and physiological signals (Rafaeli et al. 2017; Zeng et al. 2009), and more work is being presently done. Again, different tasks/jobs require different need for empathy. Some tasks require emotion, experience, critical thinking, and judgment, requiring human empathy (Enz and Siguaw 2000). Currently, service employees are still needed to augment service robots, especially in their emotional and customization tasks (Huang and Rust 2018). However, with the continuing advances in AI, the capabilities of service robots will be strengthened in a more human and empathic direction. In the future, robots with empathic intelligence will provide better and autonomously personal attention to humans.

\section{Conclusions}

With the new advances in AI and other digital technologies, continuous decrease of hardware costs, the rise of $5 \mathrm{G}$ networks, and the current pandemic crisis, service robots will become much more widely used and accepted, at a much faster pace than ever thought possible. In the past, the main reasons for using robots were: increasing the efficiency and accuracy, shortening the service time, and taking over dull, dangerous, dirty, and unsafe tasks. The last reason given above used to be more for industrial robots, but the current pandemic has created an entirely new normal where many new applications and the increased importance of service robots became prevalent for the safety from the virus (Hrynowski 2020). The pandemic, actually, may have created a turning point for the adoption of service robots in areas like healthcare, food delivery, and public safety (Talk and Lew 2020). The reason is not only because of the immediate need and many new uses of robots, but also, as robots are used more frequently, people's perceptions and acceptance of robots 
changed dramatically, much faster than pre-pandemic expectations. There are still many challenges ahead for the adoption of robots in most service industries, tasks that designers and businesses need to overcome. The knowledge of what customers want, expect, and like about service robots (the focus of this study) is the critical point of departure for overcoming some of the roadblocks to not only the final step (the adoption/use), but the first step (designing robots).

This research contributes to the literature of service management, especially application of robots in the service sector. There is a paucity of empirical studies on the service quality of robots. This study empirically explored service quality of robots, and it found that assurance and reliability are the two priority items to improve to deliver quality service to customers using robots, while tangibles and empathy are not significant, indicating that their future improvements would most likely be challenging as these constructs are multi-dimensional and depend on developments in many disciplines. Even though customers appeared to be significantly dissatisfied with responsiveness of service robots, this quality construct does not appear to be of a high priority to customers.

The findings of the study also offer managerial implications, as they provide new insights for managers on how robots can effectively be deployed to meet the quality service expected by customers. This research demonstrates that when service robots are widely deployed, providing reliable and trusted service is the most important and basic goal. The answer to the question of whether tangibles and empathy quality dimensions of service robots should be improved it would depend on the type of service and customers' unique requirements. Different types of services may require different levels of tangibles and empathy. Strategic evaluation of such consideration is needed before wide applications of service robots. For example, what is the need of intimate and humanoid robots for caring for senior citizens? Answering this question may require more research in several disciplines inducing AI, convergence technology, healthcare, psychology, gerontology, housing, and the like.

This study, like most research works, has some limitations. First and foremost, this study focused on the service quality provided by specific type of service robots (the automatic check-in system and robot arm for baggage storage) in a hotel in Taiwan. A similar study dealing with different type of robots (e.g., retailing assistants, sushi makers, healthcare helpers, etc.) or in different type of service industries, the results might be quite different. Also, this study was based on the perceptions of a sample of hotel guests at a given point in time. As tourists become more familiar with service robots, their perceptions about service robots and their service quality may also change. Thus, a longitudinal study is needed to capture a more robust results about the dynamic nature of customers' perception of the value provided by service robots. People's perception of technological innovation is a function of their cultural, psychological, and experiential background. Thus, it would be interesting to perform a comparative study of service robots in different cultural settings in different regions. These limitations of the study offer the opportunities to conduct future research in the related topics. As technologies advance rapidly, especially in AI, robotics, nanoscience, and design thinking, the functionality of robots will improve significantly. Thus, the relationships between the application of service robots and advances in related technologies would be another important future research area. 
Although this study makes contributions to the literature, it has two obvious limitations. First, to really see the service robots' quality of service in full force, this study used Chase Walker Hotel, an automated hotel with no human staff. However, that also made impossible to collect data on the service quality of human workers to conduct a comparative study with that provided by service robots, which opens opportunity for future research on comparing human and robot service quality. Second, this study did not consider task complexity, which for the purpose of this study was sufficient. However, when we discussed our findings, we also discussed how some of quality constructs could be closely related to the type of tasks. Therefore, future research can explore collecting data from a variety of robots, performing different tasks, autonomously or along with humans, and in different service industries. Other research works can focus on how service robots will affect jobs and employment, public health economic impacts, raising the issues of policies and regulations. We are at the start of a new era and new revolution, where AI and robots will enhance people's quality of life, but we should tread carefully.

\section{References}

Al-Hawari M, Ward T (2006) The effect of automated service quality on Australian banks' financial performance and the mediating role of customer satisfaction. Mark Intell Plan 24(2):127-147

Asubonteng P, McCleary K, Swan J (1996) SERVQUAL revisited: a critical review of service quality. J Serv Mark 10(6):62-81

Athanassopoulos A, Gounaris S, Stathakopoulos V (2001) Behavioural responses to customer satisfaction: an empirical study. Eur J Mark 35(5/6):687-707

Baisch S, Kolling T, Schall A, Rühl S, Selic S, Kim Z, Rossberg H, Klein B, Pantel J, Oswald F, Knopf M (2017) Acceptance of social robots by elder people: does psychosocial functioning matter? Int J Soc Robot 9(2):293-307

Bartneck C, Kulić D, Croft E, Zoghbi S (2009) Measurement instruments for the anthropomorphism, animacy, likeability, perceived intelligence, and perceived safety of robots. Int J Soc Robot 1(1):71-81

Baldwin R (2019) The globotics upheaval: globalization, robotics, and future of work. Oxford University Press, New York

Berry L, Zeithaml V, Parasuraman A (1990) Five imperatives for improving service quality. MIT Sloan Manag Rev 31(4):29-38

Bloemer J, De Ruyter K, Wetzels M (1999) Linking perceived service quality and service loyalty: a multi-dimensional perspective. Eur J Mark 33(11/12):1082-1106

Bolton R, McColl-Kennedy J, Cheung L, Gallan A, Orsingher C, Witell L, Zaki M (2018) Customer experience challenges: bringing together digital, physical and social realms. J Serv Manag 29(5):776-808

Čaić M, Odekerken-Schröder G, Mahr D (2018) Service robots: value co-creation and co-destruction in elderly care networks. J Serv Manag 29(2):178-205

Calderone L (2019) What are service robots? RoboticsTomorrow. https://www.roboticstomorrow.com/ article/2019/02/what-are-service-robots/13161. Accessed 30 April 2020

Chase R (1978) Where does the customer fit in a service operation? Harv Bus Rev 56(6):137-142

Choi S, Kim J (2018) A comparative analysis of electronic service quality in the online open market and social commerce: the case of Korean young adults. Serv Bus 12(2):403-433

Choi Y, Choi M, Oh M, Kim S (2019) Service robots in hotels: understanding the service quality perceptions of human-robot interaction. J Hosp Mark Manag. https://doi.org/10.1080/19368 623.2020.1703871

Churchill G Jr, Surprenant C (1982) An investigation into the determinants of customer satisfaction. J Mark Res 19(4):491-504

Cronin J Jr, Taylor S (1992) Measuring service quality: a reexamination and extension. J Mark 56(3):55-68 
Darling K (2012) Extending legal protection to social robots: the effects of anthropomorphism, empathy, and violent behavior towards robotic objects, paper presented at We Robot Conference, 23 April, University of Miami, Coral Gables. https://gunkelweb.com/coms647/texts/darling_robot_rights.pdf

Edvardsson B, Frow P, Jaakkola E, Keiningham T, Koskela-Huotari K, Mele C, Tombs A (2018) Examining how context change foster service innovation. J Serv Manag 29(5):932-955

Enz C, Siguaw J (2000) Best practices in service quality. Cornell Hotel Restaur Adm Q 41(5):20-29

Frick W (2015) When your boss wears metal pants. Harv Bus Rev 93(6):84-89

Gale A, Mochizuki T (2019) Robot hotel loses love for robots. Wall Street Journal. https://www.wsj.com/ articles/robot-hotel-loses-love-for-robots-11547484628. Accessed 2 April 2020

Garcia E, Jimenez M, De Santos P, Armada M (2007) The evolution of robotics research. IEEE Robot Autom Mag 14(1):90-103

Garvin D (1984) What does "product quality” really mean. MIT Sloan Manag Rev 26(1):25-43

Gidhagen M, Persson Ridell O, Sörhammar D (2011) The orchestrating firm: value creation in the video game industry. Manag Serv Qual 21(4):392-409

Grewal D, Motyka S, Levy M (2018) The evolution and future of retailing and retailing education. J Mark Educ 40(1):85-93

Grönroos C (1984) A service quality model and its marketing implications. Eur J Mark 18(4):36-44

Grönroos C (1990) Service management and marketing: managing the moments of truth in service competition. Lexington Books, Lexington

Haidegger T, Barreto M, Gonçalves P, Habib M, Ragavan S, Li H, Vaccarella A, Perrone R, Prestes E (2013) Applied ontologies and standards for service robots. Rob Auton Syst 61(11):1215-1223

Harkness J (2011) Guidelines for best practice in cross-cultural surveys. Survey Research Center, University of Michigan Inst for Social Research, Ann Arbor

Hemmington N, Kim P, Wang C (2018) Benchmarking hotel service quality using two-dimensional importance-performance benchmark vectors (IPBV). J Serv Theory Pract 28(1):2-25

Hrynowski Z (2020) Increased use of low-contact services may prove permanent. Gallup. https://news. gallup.com/poll/309203/increased-low-contact-services-may-prove-permanent.aspx. Accessed 20 June 2020

Huang M, Rust R (2018) Artificial intelligence in service. J Serv Res 21(2):155-172

Hung S, Cheng M, Chiu P (2019) Do antecedents of trust and satisfaction promote consumer loyalty in physical and virtual stores? a multi-channel view. Serv Bus 13(1):1-23

Hwang C, Yoon K (1981) Methods for multiple attribute decision making. Multiple attribute decision making. Springer, Heidelberg, pp 58-191

International Federation of Robotics (2016) Service robot, provisional definition of service robots. https:// www.ifr.org/service-robots/

International Organization for Standardization (2012) Robots and robotic devices-vocabulary. https:// www.iso.org

Keating B, McColl-Kennedy J, Solnet D (2018) Theorizing beyond the horizon: service research in 2050. J Serv Manag 29(5):766-775

Koceski S, Koceska N (2016) Evaluation of an assistive telepresence robot for elderly healthcare. J Med Syst 40(5): 121

Kogut B, Zander U (1992) Knowledge of the firm, combinative capabilities, and the replication of technology. Organ Sci 3(3):383-397

Kooijmans T, Kanda T, Bartneck C, Ishiguro H, Hagita N (2007) Accelerating robot development through integral analysis of human-robot interaction. IEEE Trans Robot 23(5):1001-1012

Laowattana, D (2020) Service robots head to pandemic's frontlines. Meet FACO: new breed of AI-powered, multi-tasking service robots. Asian Robotic Review. https://asianroboticsreview.com/home3 41-html. Accessed 24 June 2020

Lechevalier S, Nishimura J, Storz C (2014) Diversity in patterns of industry evolution: how an intrapreneurial regime contributed to the emergence of the service robot industry. Res Policy 43(10):1716-1729

Lee M, Forlizzi J, Rybski P, Crabbe F, Chung W, Finkle J, Glaser E, Kiesler S (2009) The snackbot: documenting the design of a robot for long-term human-robot interaction. In: HRI '09 Proceedings of the 4th ACM/IEEE international conference on Human Robot Interaction in La Jolla, California, 2009, Association for Computing Machinery, New York, pp 7-14

Lee S, Lee D (2019) "Untact": a new customer service strategy in the digital age. Serv Bus 13(1):1-22

Leite I, Pereira A, Mascarenhas S, Martinho C, Prada R, Paiva A (2013) The influence of empathy in human-robot relations. Int J Hum Comput Stud 71(3):250-260 
Lewis B, Mitchell V (1990) Defining and measuring the quality of customer service. Mark Intell Plan 8(6): 11-17

Lovelock C (1992) Managing services: marketing, operations, and human resources (2, nd edn. Prentice Hall, Englewood Cliffs, New Jersey

Matarić M (2017) Socially assistive robotics: human augmentation versus automation. Sci Robot 2(4): $1-2$

Matthews, K (2020) Pandemic proves utility of a wide range of service robots. The Robot Report. https://www.therobotreport.com/pandemic-proves-utility-wide-range-service-robots/. Accessed 25 June 2020

Novak T, Hoffman D (2019) Relationship journeys in the internet of things: a new framework for understanding interactions between consumers and smart objects. J Acad Mark Sci 47(2):216-237

Norman G, Streiner D (2008) Biostatistics: the bare essentials. PMPH-USA, Raleigh

Oliver R (1980) A cognitive model of the antecedents and consequences of satisfaction Decision. J Mark Res 17(4):460-469

Oliver R, DeSarbo W (1988) Response determinants in satisfaction judgement. J Consum Res 14(4):495-507

Orel F, Kara A (2014) Supermarket self-checkout service quality, customer satisfaction, and loyalty: empirical evidence from an emerging market. J Retail Consum Serv 21(2):118-129

O'Neill, S (2020) Contactless tech promises to be travel's next big thing: what's real and what's hype? Skift. https://skift.com/2020/06/04/contactless-tech-promises-to-be-travels-next-big-thing-whats -real-and-whats-hype/. Accessed 23 May 2020

Palvia S, Vemuri V (2016) Forecasts of jobless growth: facts and myths. J Inf Technol Case Appl Res 18(1):4-10

Parasuraman A, Berry L, Zeithaml V (1991) Refinement and reassessment of the SERVQUAL scale. J Retail 67(4):420-450

Parasuraman A, Zeithaml V, Berry L (1985) A conceptual model of service quality and its implications for future research. J Mark 49(4):41-50

Parasuraman A, Zeithaml V, Berry L (1988) Communication and control processes in the delivery of service quality. J Mark 52(2):35-48

Rafaeli A, Altman D, Gremler D, Huang M, Grewal D, Iyer B, Parasuraman A, de Ruyter K (2017) The future of frontline research: invited commentaries. J Serv Res 20(1):91-99

Ray G, Muhanna W, Barney J (2005) Information technology and the performance of the customer service process: a resource-based analysis. MIS Q 29(4):625-652

Regan W (1963) The service revolution. J Mark 27(3):57-62

Reiser U, Connette C, Fischer J, Kubacki J, Bubeck A, Weisshardt F, Jacobs T, Parlitz C, Hagele M, Verl A (2009) Care-O-bot ${ }^{\circledR}$ 3-creating a product vision for service robot applications by integrating design and technology, In: IEEE/RSJ International Conference on Intelligent Robots and Systems in St. Louis, MO, 2009, IEEE, New Jersey, pp 1992-1998

Podsakoff P, Organ D (1986) Self-reports of organizational research: problems and prospects. J Manag 12(4):531-544

Sampson S (2001) Understanding service businesses: applying principles of the unified services theory, 2nd edn. Wiley, New York

Sanchez J, Brock P (1996) Outcomes of perceived discrimination among Hispanic employees: is diversity management a luxury or a necessity? Acad Manag J 39(3):704-719

Santos J (2003) E-service quality: a model of virtual service quality dimensions. Manag Serv Qual 3(3):233-246

Setia P, Venkatesh V, Joglekar S (2013) Leveraging digital technologies: how information quality leads to localized capabilities and customer service performance. MIS Q 37(2):565-590

Shahin A (2006) SERVQUAL and model of service quality gaps: a framework for determining and prioritizing critical factors in delivering quality services. In: Partha Sarathy V (ed) Service quality: an introduction. ICFAI University Press, Hyderabad, pp 117-131

Sheppard B, Edson J, Kouyoumjian G (2017) More than a feeling: ten design practices to deliver business value. McKinsey \& Company, December

Sheppard B, Sarrazin H, Kouyoumjian G, Dore F (2018) The business value of design. McKinsey \& Company, October

Svensson G (2006) New aspects of research into service encounters and service quality. Int J Serv Ind Manag 17(3):245-257 
Talk B, Lew E (2020) Pandemic and the smarter world: a future of robots? Columbia Business School, Ideas and Insights. https://www8.gsb.columbia.edu/articles/brand-talk/pandemic-and-smarter-world -future-robots. Accessed 24 June 2020

Teas K (1993) Consumer expectations and the measurement of perceived service quality. J Serv Prof Mark 8(2):33-54

Vanniarajan T, Anbazhagan B (2007) SERVPERF analysis in retail banking. In: International Marketing Conference on Marketing \& Society, IIMK, India, pp 725-736

Vargo S, Lusch R (2004) Evolving to a new dominant logic for marketing. J Mark 68(1):1-17

Waytz A, Cacioppo J, Epley N (2010) Who sees human? the stability and importance of individual differences in anthropomorphism. Perspect Psychol Sci 5(3):219-232

Wirtz J, Patterson P, Kunz W, Gruber T, Nhat LuV, Paluch S, Martins A (2018) Service robots in the front line: will it be a brave new world? J Serv Manag 29(5):907-931

Wisniewski M (1996) Measuring service quality in the public sector: the potential for SERVQUAL. Total Qual Manag 7(4):357-366

Zalama E, García-Bermejo J, Marcos S, Domínguez S, Feliz R, Pinillos R, López J (2014) Sacarino, a service robot in a hotel environment. In: First Iberian Robotics Conference in ROBOT2013. Springer, Cham, Switzerland, pp 3-14

Zeithaml V, Berry L, Parasuraman A (1988) Communication and control processes in the delivery of service quality. J Mark 52(2):35-48

Zeithaml V, Berry L, Parasuraman A (1993) The nature and determinants of customer expectations of service. J Acad Mark Sci 21(1):1-12

Zeng Z, Pantic M, Roisman G, Huang T (2009) A survey of affect recognition methods: audio, visual and spontaneous expressions. IEEE Trans Pattern Anal Mach Intell 31(1):39-58

Publisher's Note Springer Nature remains neutral with regard to jurisdictional claims in published maps and institutional affiliations. 